\title{
Calculation Model and Numerical Validation of Horizontal Capacity of Micropiles with Different Section Forms
}

\author{
Wan-li Chao, ${ }^{1}$ Jin Yang $\mathbb{D},{ }^{1}$ Wen-jie Liu $\mathbb{D},{ }^{1}$ Shi-qiang Pan, ${ }^{1}$ Zong-wei Deng, ${ }^{2}$ Yu-xuan Jin, \\ and Gui-hai Fu' \\ ${ }^{1}$ Hunan Communications Research Institute Co., Ltd., Changsha 410007, China \\ ${ }^{2}$ College of Civil Engineering, Hunan City University, Yiyang 413049, China
}

Correspondence should be addressed to Jin Yang; fay99e@163.com and Wen-jie Liu; liuwje@163.com

Received 6 December 2021; Accepted 21 December 2021; Published 10 February 2022

Academic Editor: Mingfeng Lei

Copyright (C) 2022 Wan-li Chao et al. This is an open access article distributed under the Creative Commons Attribution License, which permits unrestricted use, distribution, and reproduction in any medium, provided the original work is properly cited.

\begin{abstract}
With the popularized application of micropile for slope reinforcement, there are many kinds of pile section form, such as single steel bar, multisteel bar, and tube. In order to obtain the theoretical calculation model of horizontal capacity of micropiles with different types, numerical simulations for two common conditions, namely, soil-soil and soil-rock, were carried out to study micropile reinforced slope's deformation and failure regulation. The dominated indicator for micropile horizontal capacity was acquired. By using the equivalence principle, four kinds of micropiles' capacity calculation model were deduced. Then, FEM numerical analysis was used for validation. The results show that the flexural capacity of micropile is a critical and dominated indicator which should be considered seriously in slope reinforcement design. When the ultimate flexural capacity is reached, the displacement of micropile reinforced slope will increase rapidly. The primary factor affecting the flexural capacity of micropiles is pile diameter, followed by section reinforcement ratio. The calculation results of the calculation model of flexural capacity proposed in this paper are close to those of numerical ones and are safer. The calculation model can provide reference for micropile selecting and slope reinforcement design, especially for quick design of emergency engineering.
\end{abstract}

\section{Introduction}

A variety of slope reinforcement measures have been used in construction, including anchor rod frame, retaining wall, antislip pile, and micropile. Among all kinds of reinforcement structures, micropile is promising in the engineering field with its unique performance characteristics considering the lightening, miniaturization, and economic and environmental protection of landslide support structure projects $[1,2]$. The micropile is usually a tiny diameter bored pile with a hole diameter less than $300 \mathrm{~mm}$ and a length diameter ratio greater than 30 . High-capacity body reinforcements are used as the principal load bearing element in micropiles [3]. These bodies usually contain steel bar, steel tube, waste rail, and so forth. Because of the benefit of strong adaptability and fast construction, it is widely applied in reinforcement engineering, especially emergency engineering [4].
Traditionally, researchers believed that micropiles could only carry vertical loads in the form of tree root piles, due to the relatively large length and slenderness of micropile. In the last 30 years, with the development of micropile technology and its application in engineering, researchers have gradually recognized that micropile can carry lateral loads (see Figure 1) and its horizontal capacity is essential to its operational performance [5-7].

At present, the horizontal capacity calculation method of micropile can be roughly divided into three categories: the method based on the calculation theory of ordinary antislip piles, the equivalence method, and the numerical calculation method. The first method originates from the pile-soil interaction theory of general passive piles, which can be applied to the case where the micropiles are arranged more sparsely and cannot form a monolithic structure with the soil. Multiple theories have been developed for analyzing the mechanical behavior. In early development, the mechanical 


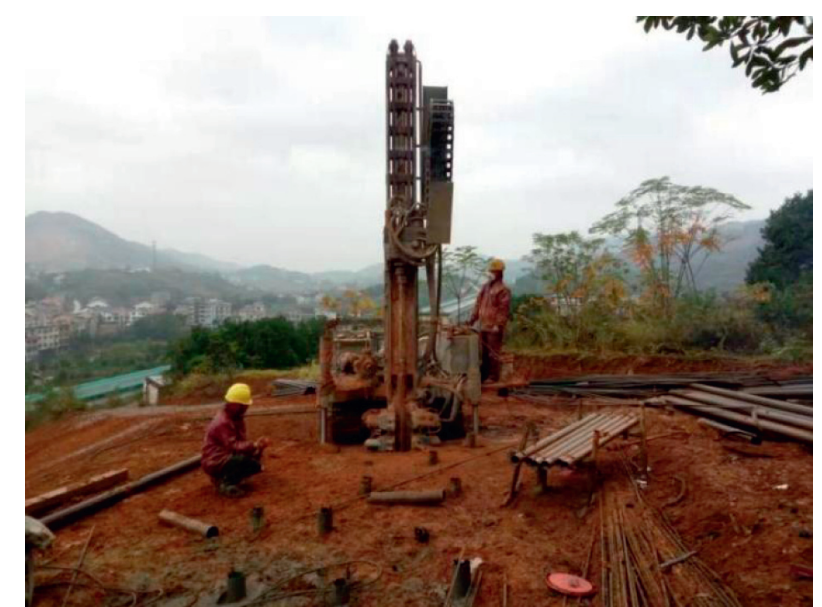

FIgURE 1: Construction process of micropiles' reinforced slope (Hunan Lou-Di, China).

response of a single pile subjected to lateral loads was investigated [8]. With further research, the nonlinear behavior of laterally loaded pile groups was analyzed based on the semianalytical or Winkler elastic method $[9,10]$. Some works were carried out on uplift load capacity recently, including single and group calculation method [11].

The equivalence method considered traditional retaining structure as a whole composite structure for the micropile group with small pile spacing that the micropile and the surrounding soil form a whole structure to bear the load together. The calculation method can be developed based on the calculation method of this retaining structure [12-14]. It can be further divided into the following methods according to the different equivalence methods:

(1) Reinforced concrete beam method: this method is a semiempirical and semitheoretical method. The composite structure of the micropile and the rocksoil body around the pile is treated as a reinforced concrete beam and analyzed according to the calculation method of the reinforced concrete beam. The equations are given without the pile-soil adhesion. Meanwhile, the empirical calculation formula is proposed considering the partial adhesion between pile and soil.

(2) Equivalent section method: this method considers the micropile combined structure as a flexible retaining wall. It carries out the design verification based on the calculation theory of retaining walls and the principle of equal deformation.

(3) Equivalent stiffness method: this method equates the small combination pile to a certain thickness of underground continuous wall according to equal flexural stiffness.

Numerical analysis can simulate the actual working conditions, which is the most rigorous solution and the most potential calculation method. Chen el al. [15] carried out numerical simulation of the flexible micropile ( $1 / d$ more than 50 in general) with finite element software ABAQUS. It is shown that the larger the diameter and the larger the friction angle of soil, the larger the lateral bearing capacity of micropiles. Lee et al. [16] investigated the behaviour of piled raft installed in soft clay using a 3D finite element analysis. They demonstrated that using a limited number of strategically located piles increases the raft bearing capacity and reduces its settlement. Cho et al. [17] utilized 3D FEM to study the settlement behaviour of pile raft foundation in clay soils. The soil was modeled using an elastic-perfectly plastic material with the Mohr-Coulomb failure criterion, and the piles were modeled as linear elastic material. The results indicated that the average settlement of the piled raft can be effectively reduced by widely spaced piles, while the differential settlement was reduced by placing the piles within the central area of the raft. Alnuaima et al. [18] carried out FEM calculation on micropiles and verified it with centrifuge tests. Some cases were analyzed taking into account a number of factors, such as the number of micropiles, the spacing to micropile diameter, and the raft thickness. It was found that a micropile system can increase the tolerable bearing pressure by $100 \%$ compared to an isolated raft system, and an adjustment factor was introduced to account for the raft flexibility.

All these studies above have provided guidance for analyzing the horizontal capacity of micropile. However, horizontal capacity indicators for micropiles include flexural capacity, shear capacity, and uplift capacity. It is necessary to acquire the dominated indicator in preventing slope deformation and failure process. Moreover, many current calculation methods simplify micropile as steel pipe pile. In fact, nowadays different section forms are developed for micropile in order to meet different engineering demands. Reports concerning theoretical calculation model for different micropile section forms are few. In this study, the deformation and failure behaviour of slopes reinforced by micropile was firstly investigated. The dominated horizontal capacity indicator for micropile was acquired. Then, the corresponding capacity calculation models for four typical micropile section forms were deduced. Then, a numerical simulation validation work was carried out. Finally, the ultimate capacity of commonly used pile type was listed and compared, which facilitates quick determination of micropile selecting in engineering design.

\section{Dominated Capacity Indicator of Micropile in Reinforced Slope}

2.1. FEM Introduction. In order to find out which indicator is more critical and dominated for horizontal resistance of deformation and failure, FEM numerical simulations are carried out. Figure 2 shows the analytical model of the threedimensional system of micropile reinforced slope. The model consists of two stacked narrow blocks to, respectively, simulate the soil layers which are above and below the potential sliding surface of the slope. A contact surface is set between the two blocks to simulate the potential sliding surface. The model's thickness, heights of the upper and lower blocks, and the length of the upper block are represented as $s, h_{\mathrm{a}}, h_{\mathrm{b}}$, and $l$, respectively. The micropile is laid in 


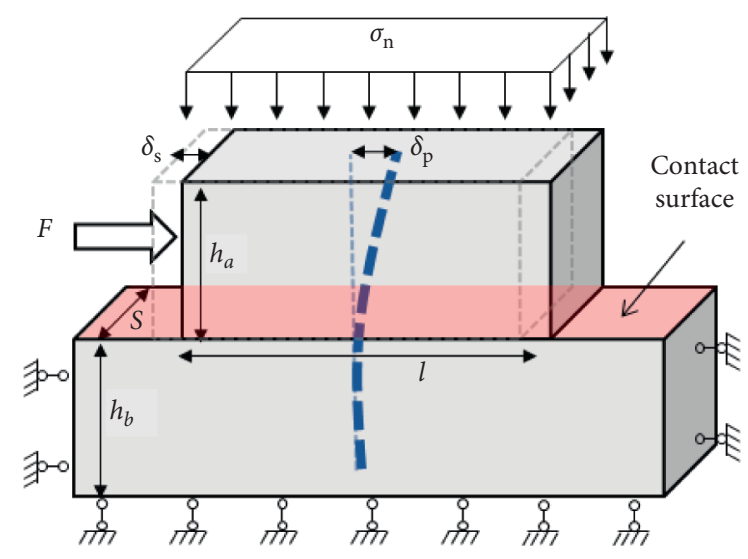

Figure 2: Analysis model of ultimate capacity of micropile.

the middle of the model through the length. The simple support constraints are set at the left, right, and lower boundaries of the lower block of the model. The model is equilibrated under the uniform load $\sigma$ applied at the upper boundary of the upper block, simulating the formation of relatively uniform Earth pressure in the model. This process aims to simplify the calculation and facilitate the analysis. Then, the horizontal uniform load, which is represented as the combined force $F$, is applied at the left boundary of the upper block to simulate the landslide thrust. Under the action of the thrust force, the horizontal displacement generated at the left boundary of the upper block is $\delta_{s}$. The horizontal displacement generated at the top of the multipile is $\delta_{\mathrm{p}}$. According to the principle of the in situ direct shear test, the horizontal thrust force $F$ is the total resistance of the micropile reinforced slope system.

Two patterns are simplified for the geological layers. The first pattern is homogeneous soil layers both above and below the sliding surface (referred to as "soil-soil pattern" hereafter). The second one is set as a homogeneous soil layer above the sliding surface and a homogeneous rock layer below the sliding surface (referred to as "soil-rock pattern" hereafter). These two soil patterns represent soil slope and soil-rock combination slope, respectively. The shear strength of the potential sliding surface is dependent on the residual strength of the soil. The cohesion and internal friction angle are discounted according to the nature of the different geological layers. The micropiles are designed using the pile unit model built into FLAC3D. The average and tangential cohesion and internal friction angles of the micropile are the same as those of the contact soil layer. The average and tangential stiffness of the contact surfaces are taken as $\mathrm{kn}=\mathrm{ks}=100 \mathrm{GPa}$ for the pile unit parameters of the different soil layer patterns, respectively [19]. The parameters for the FEM are shown in Tables 1 and 2, which are mainly estimated by several material tests according to "Standard for Geological Testing Method" [20] and "Standard for Test Method of Concrete Structures" [21].

Figure 3 shows the grid model of the resisting force analysis (only one element thickness of the model is shown). Micropile is arranged in the middle of the model with a diameter of $0.2 \mathrm{~m}$ and a pile length of $20 \mathrm{~m}$. The thickness of the model is $s=3 \mathrm{~m}$ and $h_{\mathrm{a}}=h_{\mathrm{b}}=10 \mathrm{~m}$. A uniform and horizontal load is applied to the upper and left boundaries of the upper block. The load is gradually increased.

\subsection{Analysis of Slope Resistance Results of Soil-Soil Mode with} Multipile Antislip Reinforcement. Figure 4 shows the variation curves of the total resistance (under support condition) and the sliding surface resistance (under unsupported condition) with the boundary displacement. It can be seen that the failure process of micropile supporting slope can be divided into three steps, namely, small deformation step, deflection step, and uplift step.

Take "soil-soil pattern," for example, when the horizontal thrust pressure is less than $32 \mathrm{kPa}$, and the horizontal resistance of the system is mainly provided by the shear strength of the block surface. The horizontal resistance generated by the micropile is negligible due to the small horizontal displacement. When the horizontal thrust pressure is between $32 \mathrm{kPa}$ and $40 \mathrm{kPa}$, the deflection of micropile enhances. The horizontal resistance provided by the sliding surface is constant, and the extra horizontal resistance is mainly provided by the flexural capacity of micropile. It can be seen that the micropile has obvious displacement control on the slope in the deflection step. In this step, the horizontal displacement is about $1 / 2$ of that without support.

As the pressure increases continually, the bending moment is close to the limitation, namely, ultimate flexural capacity. When the horizontal thrust pressure surpasses $40 \mathrm{kPa}$, an apparent horizontal displacement increase with nearly $40 \mathrm{~cm}$ can be observed. Therefore, the horizontal thrust pressure of $40 \mathrm{kPa}$ is the maximum when the controlled displacement of the slope is within $10 \mathrm{~cm}$. However, the micropile still possesses a considerable pullout resistance due to the relatively large shear strength between the pile and the soil. The deformation and failure process of the soil-rock slope with micropile support is similar.

In general, when the ultimate flexural capacity of micropile is reached, the displacement will increase rapidly. At the same time, the antiuplift capacity has not been fully played. Therefore, flexural capacity is the primary and dominated indicator that needs to be considered in reinforcement design.

\section{Derivation of Steel Tube Pile Flexural Capacity Formula}

3.1. Typical Section Form of Micropile. The micropile consists of cement paste and reinforcing material, and the reinforcing material generally includes steel tube and steel bar. Four typical types of micropile cross-section forms are commonly used. "M25" means that the compressive strength of the cement mortal is nearly $25 \mathrm{MPa}$. This kind of cement mortal is widely used in micropile engineering because of advantages in cost and mechanical properties. As shown in Figure 5, the reinforcing material of the A-1 and A-3 section is one steel bar and three steel bars, respectively. The reinforcing material of the $\mathrm{B}$ and $\mathrm{C}$ section is 
TABle 1: Geotechnical parameters.

\begin{tabular}{lcccc}
\hline Materials & Modulus of elasticity $E(\mathrm{MPa})$ & Poisson's ratio $V$ & Cohesion $c(\mathrm{kPa})$ & Angle of internal friction $\varphi\left(^{\circ}\right)$ \\
\hline Soil layer & 50 & 0.35 & 35 & 25 \\
Rock layer & 1000 & 0.25 & 100 & 30 \\
Sliding surface & - & - & 15 & 25 \\
\hline
\end{tabular}

TABLE 2: Micropile parameters.

\begin{tabular}{lccccc}
\hline Materials & $\begin{array}{c}\text { Pile diameter } D \\
(\mathrm{~m})\end{array}$ & $\begin{array}{c}\text { Modulus of elasticity } E \\
(\mathrm{GPa})\end{array}$ & $\begin{array}{c}\text { Poisson's ratio } \\
v\end{array}$ & $\begin{array}{c}\text { Ultimate bending moment } M_{\mathrm{u}} \\
(\mathrm{kN} \cdot \mathrm{m})\end{array}$ & $\begin{array}{c}\text { Ultimate pulling force } N_{\mathrm{u}} \\
(\mathrm{kN})\end{array}$ \\
\hline Piles & 0.2 & 50 & 0.2 & 70 & 1100 \\
\hline
\end{tabular}

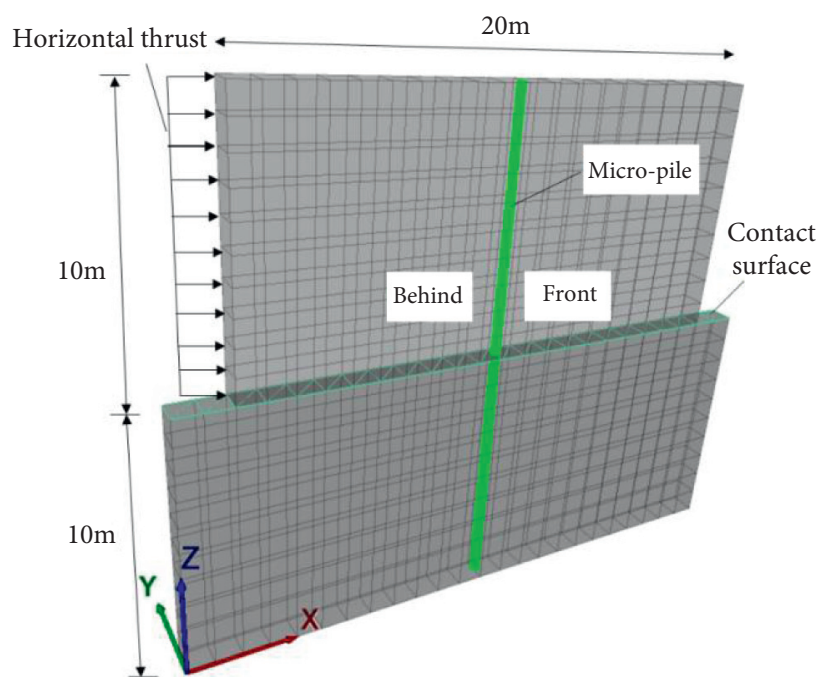

FIgURE 3: FEM grid model with one element thickness.

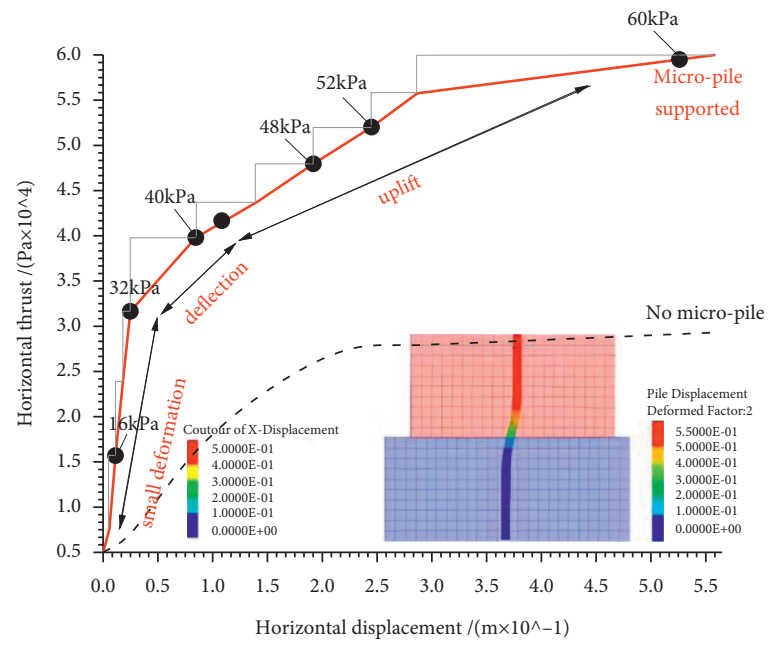

(a)

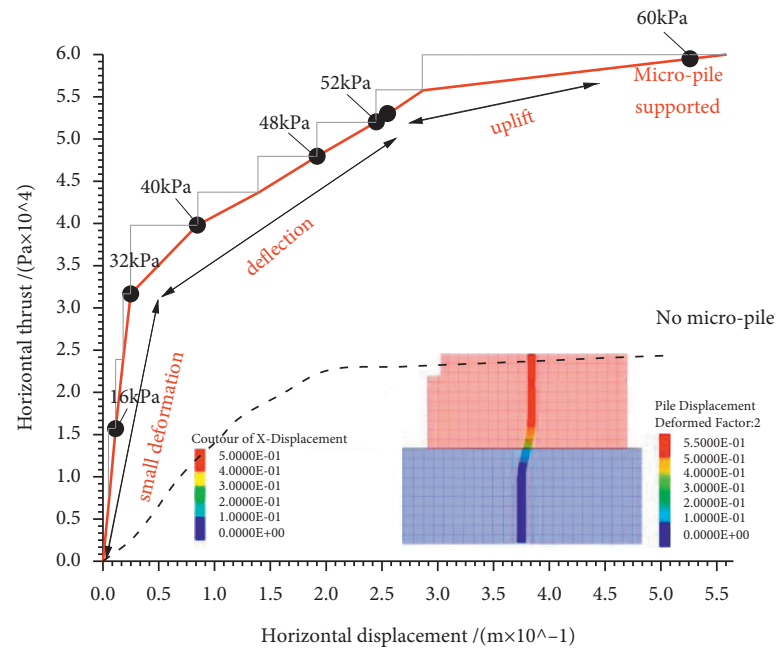

(b)

FIGURE 4: Direct shear load-displacement curve. (a) Soil-soil pattern. (b) Soil-rock pattern.

steel tube and the combination of a steel tube and three steel bars, respectively. The design parameter $H$ is the outer diameter of the steel tube, and $s$ is the distance from the shape center of the steel section to the shape center of the pile section.
3.2. Derivation of the Flexural Capacity Formula for A-1 Section. The reinforced body of the A-1 micropile section is a single reinforcement, referred to as a single reinforcement section, and the following assumptions are made to simplify the calculation: the tensile strength of the slurry in the tensile 


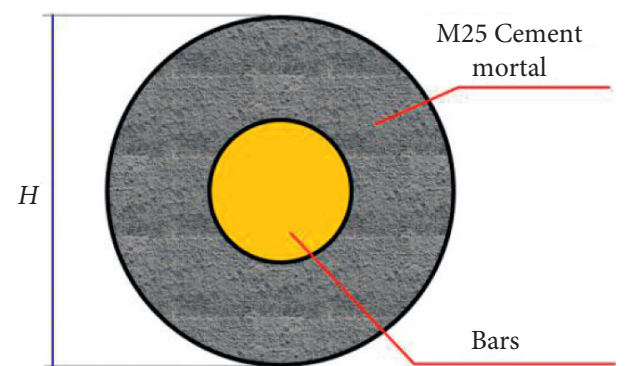

(a)

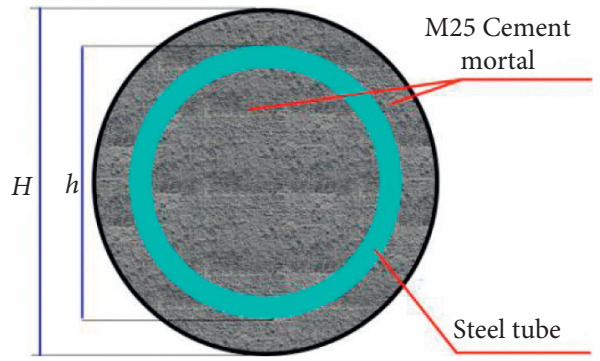

(c)

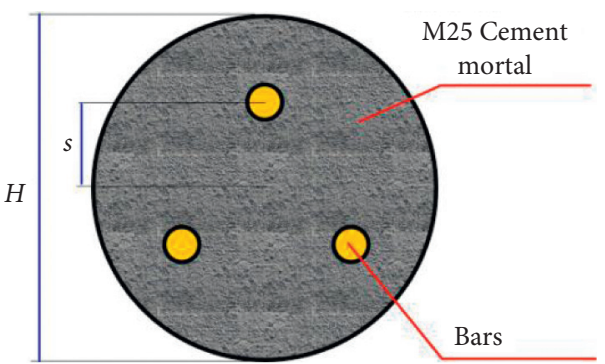

(b)

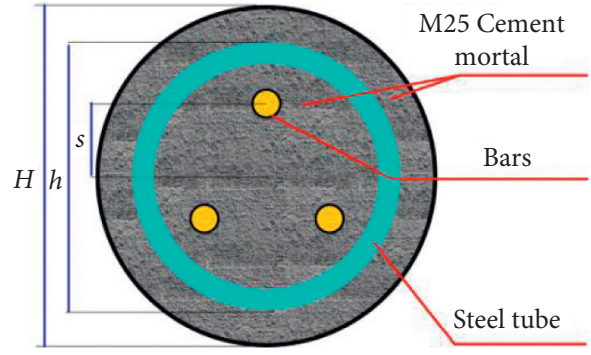

(d)

Figure 5: Section form of four typical piles. (a) Type A-1 section. (b) Type A-3 section. (c) Type B section. (d) Type C section.

zone outside the reinforcement can be disregarded since it has little effect on the ultimate bending moment. The slurry yielding occurs only in the compressive zone above the reinforcement. Therefore, the yielding area of the compressive zone can be assumed as $1 / 4$ of the total slurry area. In contrast, the stress of the slurry in other parts is relatively low and is not considered. To simplify the calculation, the circular reinforcement cross section is equivalent to the upper and lower symmetrical I-beam rectangular cross sections. The rectangular height of the web is the diameter of the reinforcement $d$. The area of both tension and compression flange is both $1 / 4$ of the total slurry area. Besides, all the slurry in the flange is assumed in compression yields, and the tensile and compressive yield stresses of the reinforcement are assumed equal. In addition, the yield stresses of the web reinforcement are assumed rectangularly distributed, as shown in Figure 6.

I-beam section size is as follows:

$$
\begin{aligned}
t & =\frac{H}{2}-\frac{d}{2}, \\
l & =\frac{A}{4 t} \\
& =\frac{\pi / 4 H^{2}-\pi / 4 d^{2}}{4 t} \\
& =\frac{\pi}{16 t}\left(H^{2}-d^{2}\right), \\
b & =\frac{\pi / 4 \cdot d^{2}}{d} \\
& =\frac{\pi d}{4},
\end{aligned}
$$

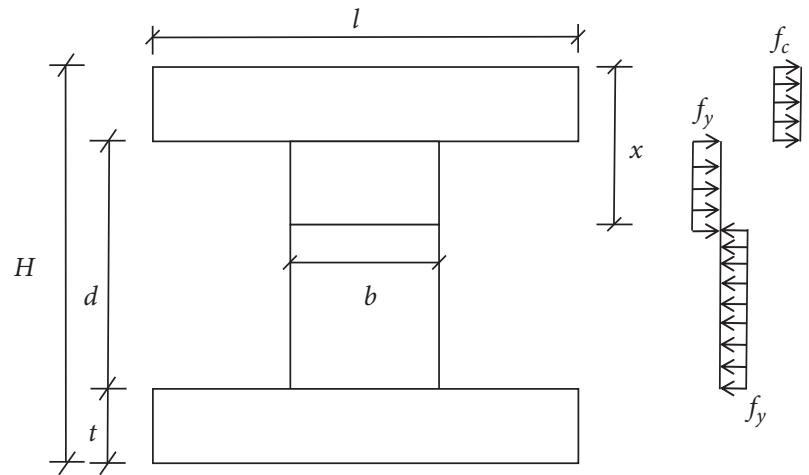

FIGURE 6: Sketch of single reinforcement section calculation.

where $t$ is the flange thickness; $l$ is the flange width; $b$ is the web width; $H$ is the pile diameter; $d$ is the reinforcement diameter; and $A$ is the total area of the slurry.

The static equilibrium conditions are presented in the following equation:

$$
f_{c} \cdot t \cdot l+f_{y} \cdot b \cdot(x-t)=f_{y} \cdot b \cdot(H-t-x) .
$$

The height of the pressure zone can be obtained from the following equation:

$$
x=\frac{H}{2}-\frac{f_{c} \cdot t \cdot l}{2 f_{y} \cdot b} .
$$

As a result, the formula for the flexural capacity of the A-1 section can be acquired:

$$
M_{u}=f_{y} \cdot b \frac{(H-t-x)^{2}}{2}+f_{y} \cdot b \frac{(x-t)^{2}}{2}+f_{c} \cdot b \cdot l\left(x-\frac{t}{2}\right) \text {, }
$$


where $f_{y}$ is the yield strength of the reinforcement; $f_{c}$ is the compressive yield strength of the slurry; and $x$ is the height of the compressed zone.

3.3. Derivation of the Flexural Capacity Formula for A-3 Section and B Section. The reinforcement body of the A-3 micropile section contains three bars, and the position of the bars is symmetrical about the shape center of the section. The flexural capacity of the micropile in this section form against bending is influenced by the direction of the load action, which will affect the final flexural capacity calculation. To avoid this situation, the reinforcement section is converted into a circular section according to the principle of static equivalence. The conversion principle of the cross section is shown in the following equation.

$$
\begin{aligned}
t & =\frac{3 \pi d^{2}}{8 \pi s} \\
& =\frac{3 d^{2}}{8 s},
\end{aligned}
$$

where $d$ is the diameter of the reinforcement; $t$ is the thickness of the equivalent steel tube; and $s$ is the distance from the shape center of the reinforcement section to the shape center of the pile section.

The circular section can be regarded as equivalent steel tube so that the flexural capacity formula of the A-3 type section is the formula of the $\mathrm{B}$ type steel tube section.

The reinforced body of the B type micropile section is steel tube. And its cross-sectional form is the same as that of the steel tube pile. Therefore, the derivation of the calculation formula of flexural capacity of the B type section is based on the formula derivation of steel tube pile. Moreover, through the numerical test, the thickness of the protective layer on the outside of the steel tube of the B type micropile is relatively large so that its provision of flexural capacity is nonnegligible. Therefore, the contribution of the thickness of the protective layer to the flexural capacity needs to be considered into the capacity calculation of $\mathrm{B}$ type section. In order to simplify the calculation, the following assumptions are made. (1) The derivation process is based on the steel tube pile flexural equation. (2) The contribution of the steel tube outer pressure zone protective layer slurry to the flexural capacity is considered. (3) The steel tube inner pressure zone height $x$ is unrelated to the pressure zone protective layer slurry. (4) The slurry in pressure zone protective layer is in the state of pressure yielding with the bowed shape. The angle of the bow span is the same as that in the steel tube inner pressure zone, shown in Figure 7.

(a) Calculation of bow section characteristics.

Calculation angle:

$$
\alpha_{1}=\frac{\pi}{2}-\alpha_{0} .
$$

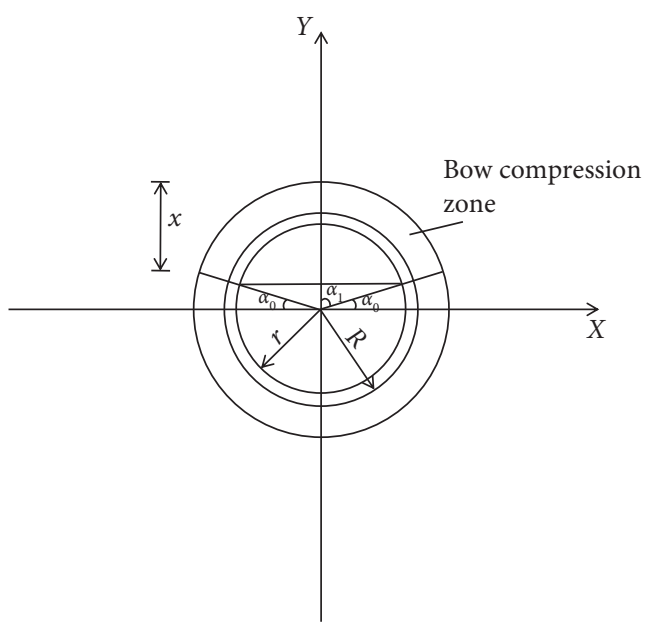

FIgURE 7: Distribution of pressure zones in B section.

Bow center position:

$$
e=\frac{2 H \sin ^{3} \alpha_{1}}{3\left(2 \alpha_{1}-\sin 2 \alpha_{1}\right)}
$$

Bow area:

$$
A_{e}=\frac{(H / 2)^{2} \cdot\left(2 \alpha_{1}-\sin 2 \alpha_{1}\right)}{2},
$$

where $\alpha 1$ is the angle between the horizontal line and the line connecting circle center with lower edge of compression zone; $\mathrm{H}$ is the pile diameter; $e$ is the distance from the center of the bow to the center of the pile; $A_{e}$ is the area of the bow.

(b) Calculation of flexural capacity.

Based on the above assumptions which are biased towards insecurity, the flexural capacity is mainly based on the bearing capacity provided by the steel tube, the core slurry body considered, and the bending moment of the bowed-to-neutral axis in the compressed zone of the protective layer. Therefore, the final expression of flexural capacity is calculated as follows:

$$
\begin{aligned}
M_{u}= & M_{s}+M_{c} \\
= & f_{y} t(R+r)^{2} \cos \alpha_{0}+\frac{2}{3} f_{c} r^{3} \cos ^{3} \alpha_{0} \\
& +f_{c} \cdot A_{e} \cdot\left(e-r \sin \alpha_{0}\right) .
\end{aligned}
$$

3.4. Derivation of Flexural Capacity Formula for C Section. The reinforced body of the $\mathrm{C}$ type micropile section is the combination of a steel tube and three reinforcement bars. Compared to B type section form, the three reinforcement bars in the $\mathrm{C}$ type section are set inside the steel tube so that they can be designed according to the design method of the $\mathrm{B}$ 
type section. Regarding safety design, the contribution of the three reinforcement bars to the flexural capacity can be calculated according to the most unfavorable flexural form, as shown in Figure 8. Therefore, the flexural capacity of the reinforcement bars can be assumed as follows. (1) The ultimate bending moment of the section is calculated by the most unfavorable flexural capacity form of the reinforcement. (2) The height $x$ of the compressive zone is unrelated to the stress on the reinforcement. (3) The stress on the reinforcement is calculated per the assumption of the flat section.

(a) Calculation of the stress in the shape of the center of the steel bar

Stress in tensile reinforcement:

$$
\sigma=\frac{s+r \sin \alpha_{0}}{R+r \sin \alpha_{0}} f_{y} .
$$

Stress in compressed reinforcement:

$$
\sigma=\frac{s / 2-r \sin \alpha_{0}}{R+r \sin \alpha_{0}} f_{y}
$$

where $s$ is the distance from the cross-sectional center of the reinforcement to the cross-sectional center of the pile; $r$ and $R$ are the inner and outer diameter of the steel tube, respectively; and $f_{y}$ is the yield strength of the reinforcement.

(b) Calculation of flexural capacity of $\mathrm{C}$ section.

Based on the above assumptions which are on the unsafe side, the flexural bearing capacity in equation (9) is based on flexural capacity provided by the steel tube and core slurry, the bow of the protective layer pressure zone, and the bending moment of the reinforcement stress on the neutral axis. Therefore, the final expression of the flexural capacity is presented in the following equation.

$$
\begin{aligned}
M_{u}= & M_{s}+M_{c} \\
= & f_{y t} t(R+r)^{2} \cos \alpha_{0}+\frac{2}{3} f_{c} r^{3} \cos ^{3} \alpha_{0}+f_{c} \cdot A \\
& \cdot\left(a-r \sin \alpha_{0}\right)+f_{y} A_{s} \\
& {\left[\frac{\left(s+r \sin \alpha_{0}\right)^{2}}{R+r \sin \alpha_{0}}+2 \cdot \frac{\left(s / 2-r \sin \alpha_{0}\right)^{2}}{R+r \sin \alpha_{0}}\right], }
\end{aligned}
$$

where $A_{s}$ is the cross-sectional area of a single bar.

\section{Numerical Validation}

As for the flexural capacity of micropile, in order to simplify the expression of the formula, there are certain assumptions in the derivation process, so it is necessary to use numerical method to verify the applicability and accuracy of the proposed formula.

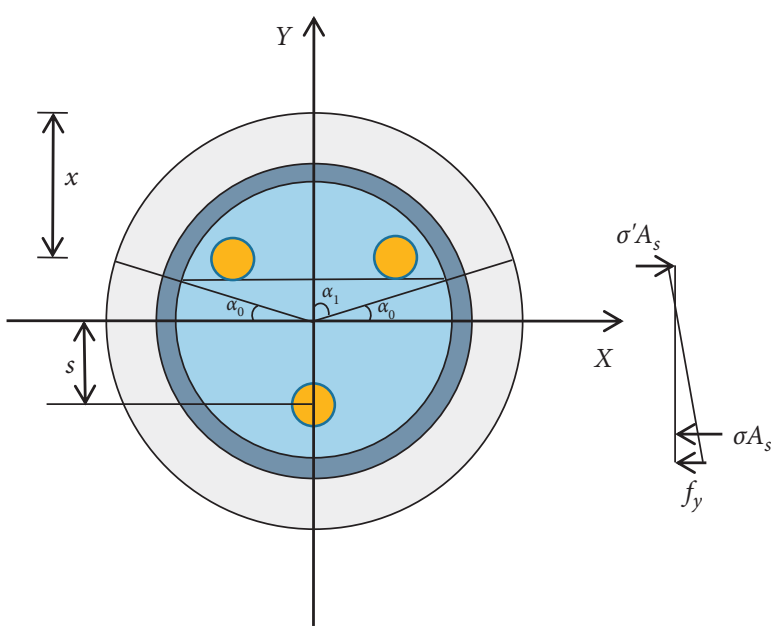

Figure 8: The most unfavourable bending section form.

4.1. Numerical Model Used for Validation. The model is a supported beam subjected to symmetrical loading which can be seen in Figure 9. The cross section in the span is in a pure bending state, and the bending moment is maximum because the mechanical model is symmetrical. After simplification, half of the mechanical model is taken for simulation. Therefore, by stepwise increasing the load $F$ until the pile bends and breaks, the maximum bending moment is obtained, which is the flexural capacity of the pile. The numerical simulation uses four typical sections to verify the proposed formula, including 100-A, 100-B, and 200-C. The yield strength of the reinforcement material is taken as $235 \mathrm{MPa}$. The compressive and tensile yield strengths of the cement mortar body are $40 \mathrm{MPa}$ and $4 \mathrm{MPa}$, respectively.

4.2. Numerical Validation of 100-A Section Flexural Resistance. The form of the 100-A section and the loading method are shown in Figure 10. The mechanical states of the pile body and the stress distributions in the left end section corresponding to the situations of $F=8 \mathrm{kN}$ and $28 \mathrm{kN}$ are shown in Figure 11. When the load is small, the cement mortar slurry is pulled apart, and then the cement mortar slurry in the tension zone starts to yield under pressure, followed by the yielding of cement mortar in the compression zone and reinforcement in the tension zone. As the load increases, the yielding range of the cement mortar slurry and the reinforcement gradually expands toward the pile core until it is damaged. Throughout the process, the displacement of the left end section gradually increases with the load increase.

The load-deflection curve of the whole process of numerical test is shown in Figure 12. The crack load is about $4.2 \mathrm{kN}$ because the stress on cement mortar surpasses its tensile yield strength. The ultimate load can be roughly derived as $24 \mathrm{kN}$, and the corresponding ultimate flexural capacity (bending moment) is $9.6 \mathrm{kN} \cdot \mathrm{m}$. Beyond this load, the deflection increases quickly. In contrast, the ultimate bending moment calculated by equation (4) is $9 \mathrm{kN} \cdot \mathrm{m}$, 


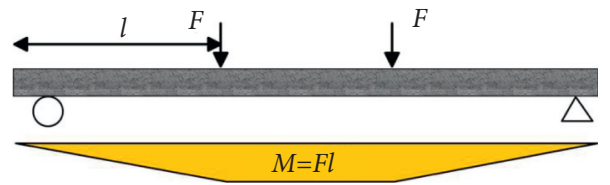

Figure 9: Mechanical models of flexural loading.

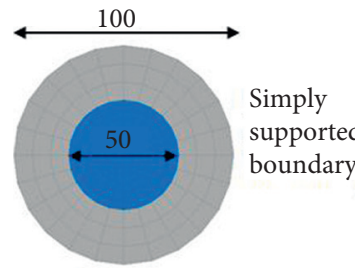

100-A Section (mm)

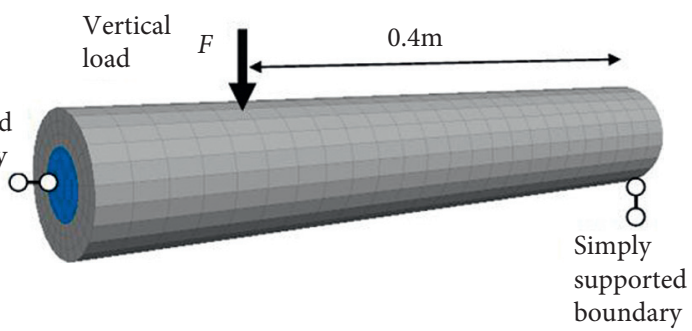

FIgURE 10: 100-A section form and loading method.
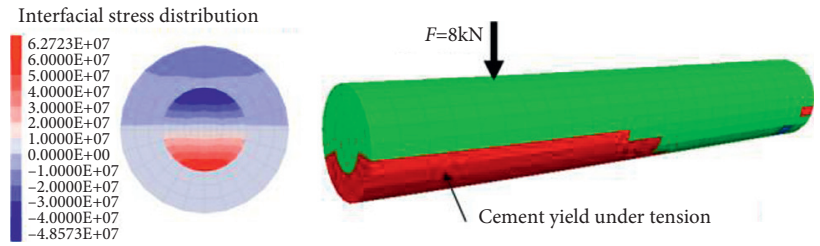

(a)

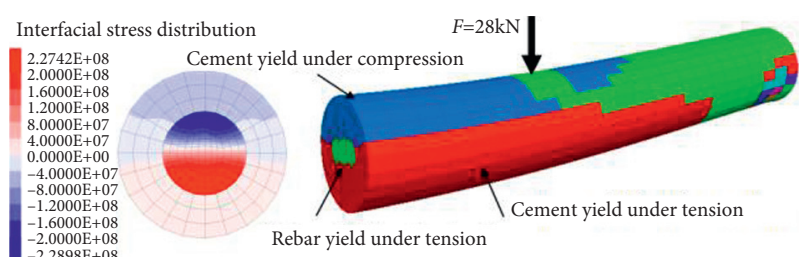

(b)

Figure 11: Mechanical states of 100-A micropile. (a) $F=8 \mathrm{kN}$. (b) $F=28 \mathrm{kN}$.

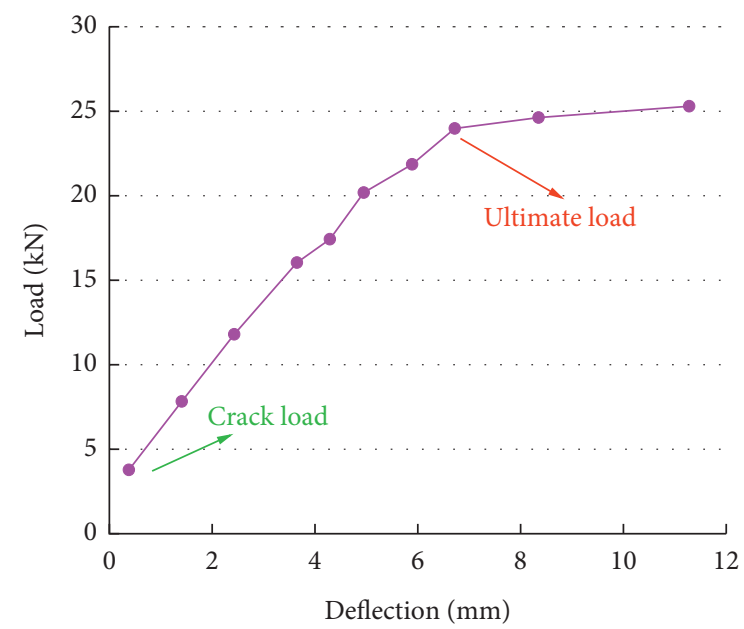

FIGURE 12: Relationship between load and deflection for 100-A.

indicating that the flexural capacity calculated by the calculation model formula is on the safe side and is close to the numerical validation result.

4.3. Numerical Validation of $100-B$ Section Flexural Resistance. The form of the 100-B section and the loading method are shown in Figure 13. The mechanical states of the pile body and the stress distributions in the left end section corresponding to the situations of the taken load $F=4 \mathrm{kN}$ and $18 \mathrm{kN}$ are shown in Figure 14, respectively. In the case of the small load, the cement mortar slurry is pulled apart, followed by the yielding of the cement mortar slurry in the compression zone under pressure. Then, the steel tube in the tension zone starts to yield. As the load increases, the yielding range of the cement mortar slurry and steel tube gradually expands toward the pile core until the structural damage.

The load-deflection curve of the whole process of numerical test is shown in Figure 15. The ultimate load can be roughly derived as $18 \mathrm{kN}$, and the corresponding ultimate bending moment is $7.2 \mathrm{kN} \cdot \mathrm{m}$. In contrast, the ultimate bending moment calculated by the calculation model formula (9) is $7 \mathrm{kN} \cdot \mathrm{m}$, which indicates that the flexural capacity calculated by the calculation model formula is on the safe side and is close to the numerical validation result.

4.4. Numerical Validation of 200-C Section Flexural Resistance. The form of the 200-C section and the loading method are shown in Figure 16. The mechanical states of the pile body and the stress distributions in the left end section corresponding to the situations of the taken load $F=40 \mathrm{kN}$ and $115 \mathrm{kN}$ are shown in Figure 17, respectively. When the load is small, the cement mortar slurry is pulled apart, and then the cement mortar slurry in the compression zone starts to yield under pressure, followed by the yielding of the steel tube in the tension zone. As the load increases, the yielding range of the cement mortar slurry and steel tube 


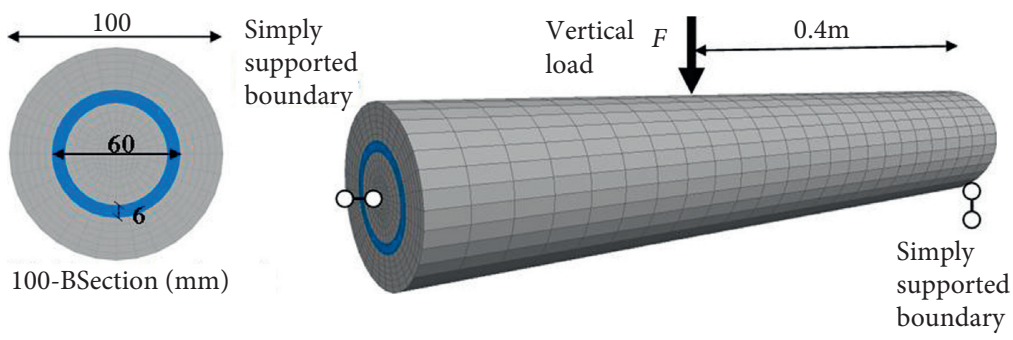

FIgURE 13: 100-B section form and loading method.

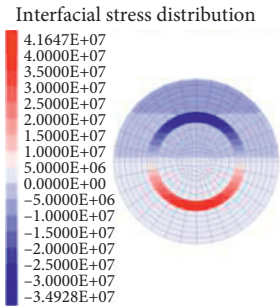

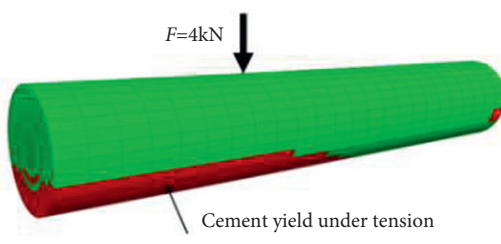

(a)

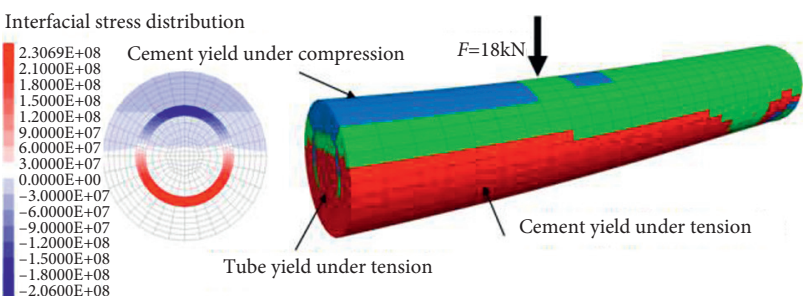

(b)

Figure 14: Mechanical states of 100-B micropile. (a) $F=4 \mathrm{kN}$. (b) $F=18 \mathrm{kN}$.

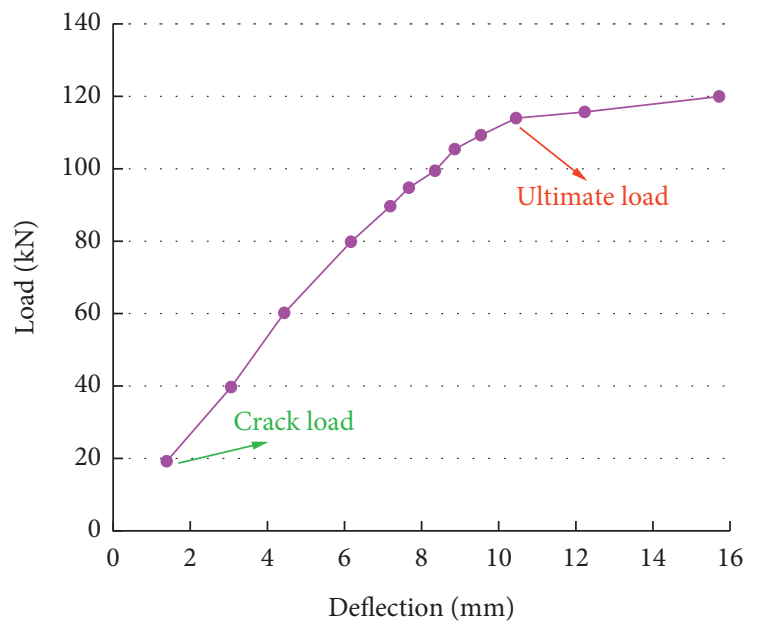

Figure 15: Relationship between load and deflection for 100-B.

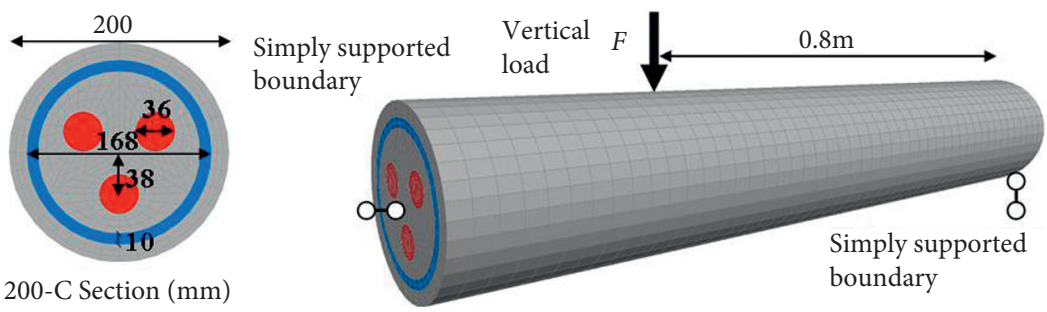

FIgURE 16: 200-C section form and loading method.

gradually expands toward the pile core until the damage. In the damage state, the stress of the steel in the tensile zone is close to the yield stress, and part of it has yielded. The steel in the compressive zone has not yielded, whereas the stress at its edge is close to the yield stress.
The load-deflection curve of the whole process of numerical test is shown in Figure 18. The ultimate load is $115 \mathrm{kN}$, and the corresponding ultimate bending moment is $92 \mathrm{kN} \cdot \mathrm{m}$. In contrast, the ultimate bending moment calculated by the calculation model formula (12) is $88.4 \mathrm{kN} \cdot \mathrm{m}$. 


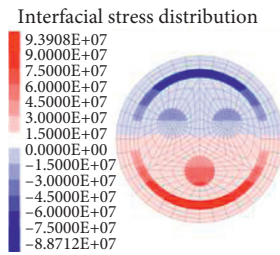

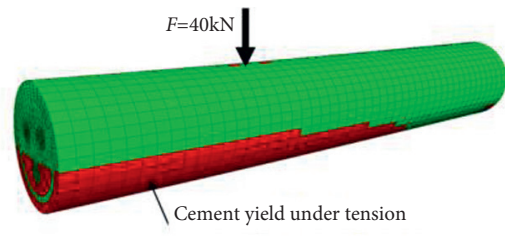

(a)

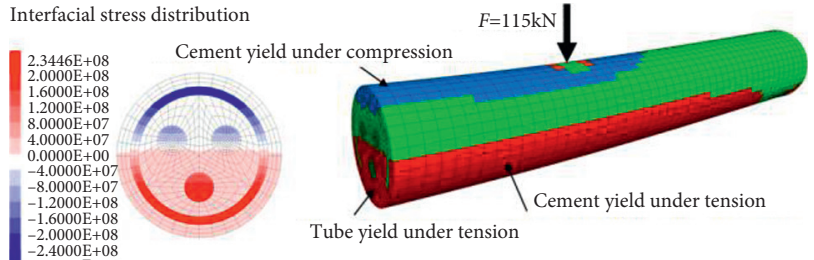

(b)

Figure 17: Mechanical states of 200-C micropile. (a) $F=40 \mathrm{kN}$. (b) $F=115 \mathrm{kN}$.

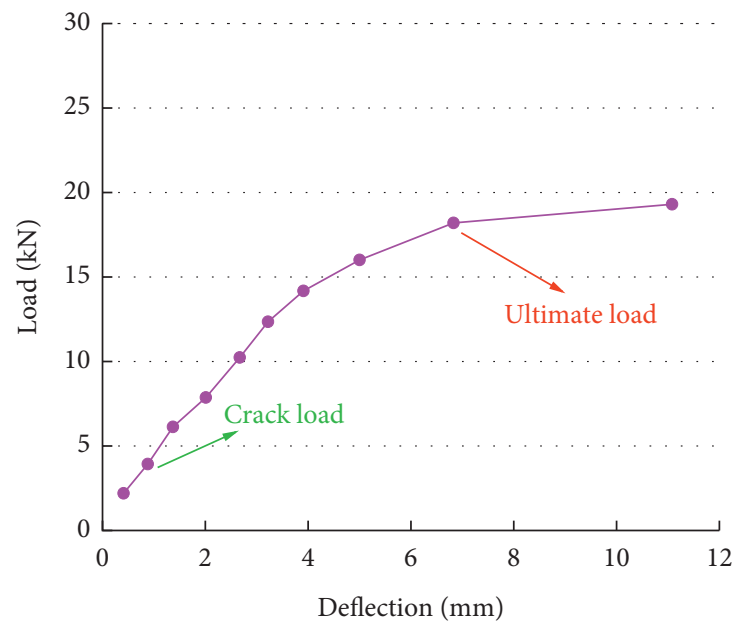

Figure 18: Relationship between load and deflection for 200-C.

TABLe 3: Flexural capacity for types A-1 and A-2.

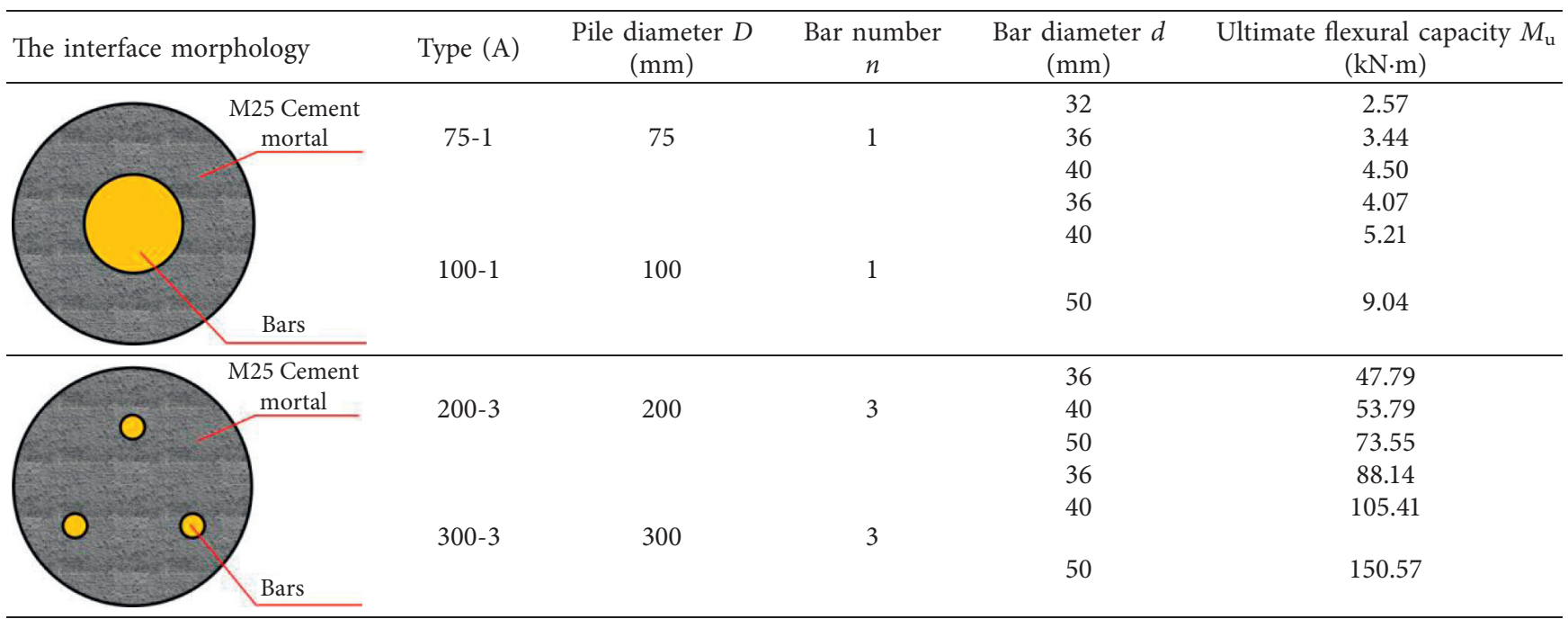

Thereby, the theoretical flexural capacity is close to the numerical validation result and is safer.

\section{Summary}

According to calculation model formula, ultimate flexural capacity for different commonly used micropiles in engineering is listed in Tables 3 and 4 and Figure 19. In Figure 19, for example, "75 mmA-1 $\varphi 32 \mathrm{~mm}$ " represents the A section form with $75 \mathrm{~mm}$ pile diameter and one bar with $32 \mathrm{~mm}$ bar diameter.

The ultimate flexural capacity calculated by calculation model formulas can be used as a reference for slope reinforcement design, especially for slope emergency engineering. It can be seen that the first important factor of ultimate flexural capacity for micropile is pile diameter, 
TABle 4: Capacity for types B and C.

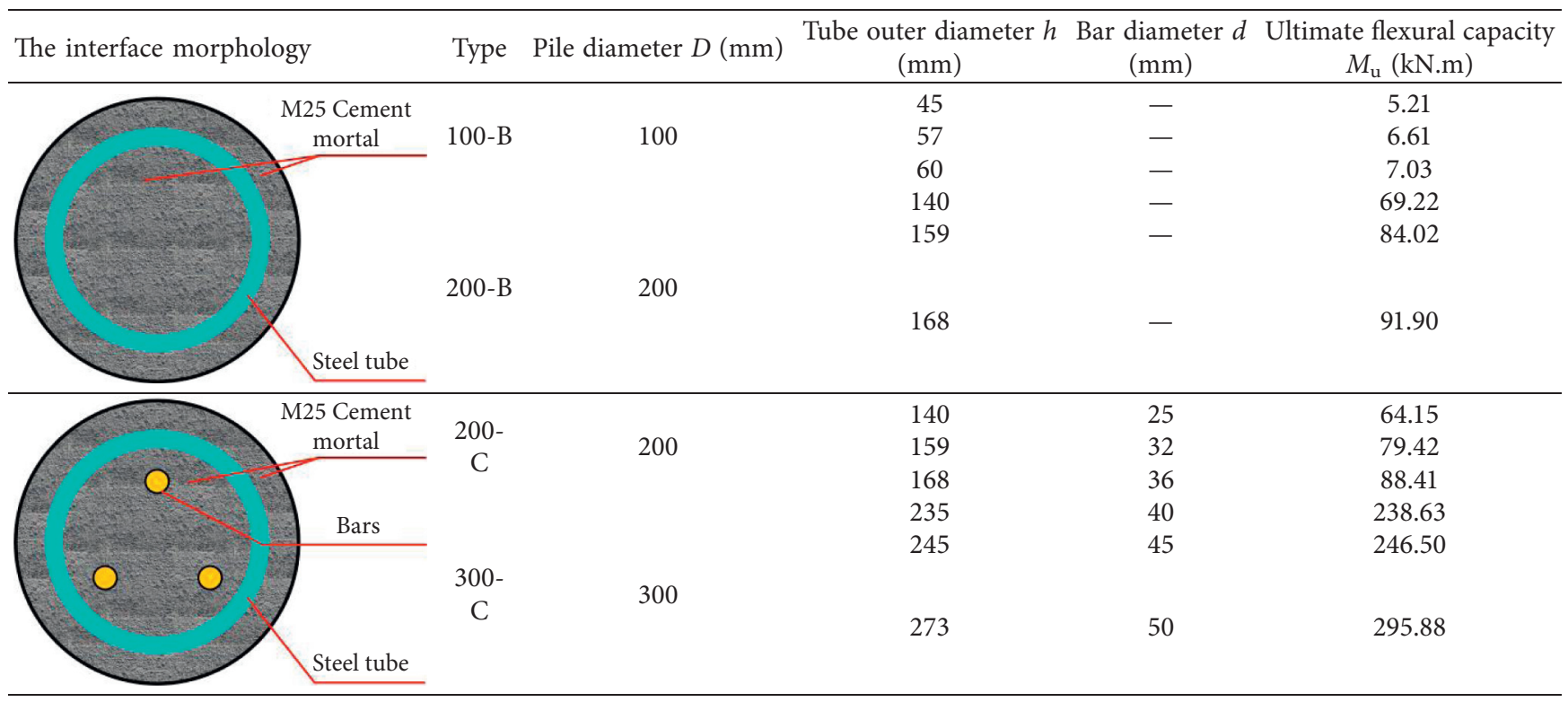

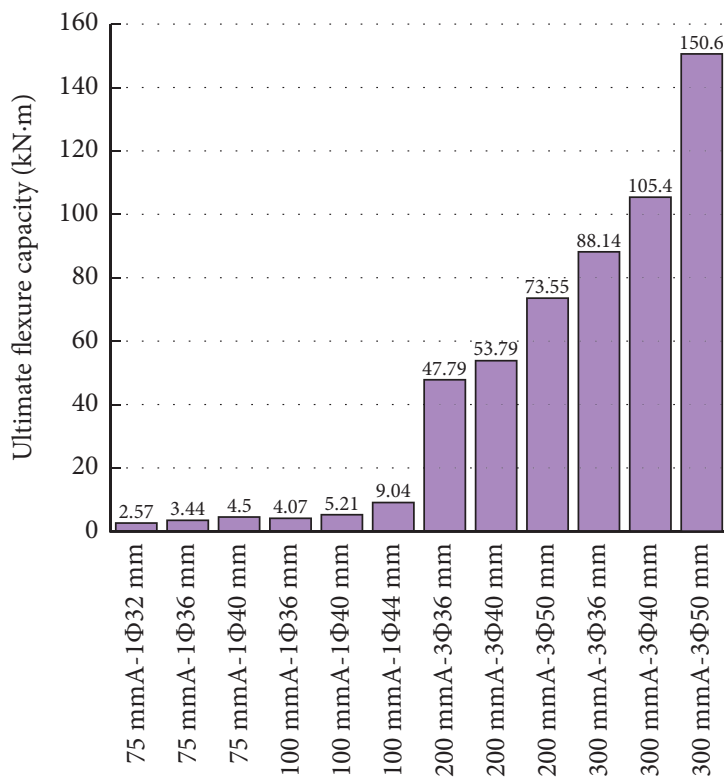

(a)

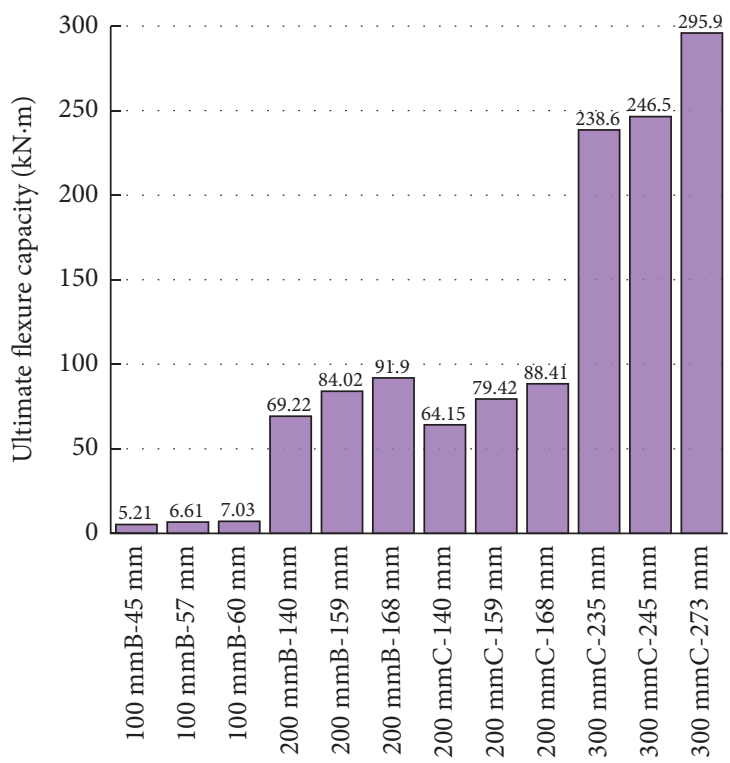

(b)

FIgURE 19: Ultimate flexural capacity of different micropiles calculated by calculation model formula. (a) A-1 and A-3. (b) B and C.

followed by the reinforcement ratio. For example, compared with $100 \mathrm{mmA}-1 \varphi 36 \mathrm{~mm}, 200 \mathrm{mmA}-3 \varphi 36 \mathrm{~mm}^{\prime \prime s} M_{\mathrm{u}}$ increases by nearly $1000 \%$. Compared with $200 \mathrm{mmA}$ $3 \varphi 36 \mathrm{~mm}, 200 \mathrm{mmA}-3 \varphi 50 \mathrm{~mm}^{\prime}$ s $M_{\mathrm{u}}$ increases by nearly $54 \%$. That is why type $\mathrm{C}$ has the highest ultimate flexural capacity.

\section{Conclusion}

The dominated indicator of micropile in slope reinforcement was acquired by numerical simulation in this paper. Various calculation model formulas to calculate the flexural capacity of different types of micropiles were proposed and validated by numerical simulation. The conclusions drawn in this study can be classified as follows:

(1) When the ultimate flexural capacity is reached, the displacement of slope reinforced by micropile will increase rapidly. At the same time, the antiuplift capacity has not been fully played. Flexural capacity is the primary and dominated indicator that needs to be considered in reinforcement design.

(2) The crack load for micropile is easy to be reached because of low tensile strength of cement mortar. The whole micropile tends to reach ultimate flexural capacity when rebar or tube reaches yield limit. 
(3) According to the summary of ultimate flexural capacity, it can be seen that $M_{u}$ for A-1 is very small and it is not suitable for using in reinforcement engineering with large horizontal force.

(4) The first important factor of ultimate flexural capacity for micropile is pile diameter, followed by reinforcement ratio. That is why type $\mathrm{C}$ has the highest ultimate flexural capacity.

(5) The calculation results from calculation model formula are close to numerical ones and tends to be safer, so it has application values in micropile selecting and slope reinforcement design, especially for slope emergency engineering.

\section{Data Availability}

The data used to support the findings of this study are available from the corresponding author upon request.

\section{Conflicts of Interest}

The authors declare that they have no conflicts of interest.

\section{Acknowledgments}

This work was supported by Hunan Transportation Science and Technology Project (201501 and 201907), the Natural Science Foundation of Hunan Province, China (2020JJ4156 and 2021JJ50142), and the National Natural Science Foundation of China (51674041 and 51474103).

\section{References}

[1] K. T. Chau, C. Y. Shen, and X. Guo, "Nonlinear seismic soilpile-structure interactions:shaking table tests and FEM analyses," Soil Dynamics and Earthquake Engineering, vol. 29, no. 2, pp. 300-310, 2008.

[2] Y. Mascarucci, S. Miliziano, and A. Mandolini, "A numerical approach to estimate shaft friction of bored piles in sands," Acta Geotechnica, vol. 9, no. 3, pp. 547-560, 2014.

[3] X. J. Su, "Study on the treatment effect of micro-pile strengthening tunnel creep mountain," Geotechnical Foundation, vol. 32, no. 5, pp. 480-483, 2018, in Chinese.

[4] G. S. Ghataora, L. Lee, and U. K. Ling, "Changes in properties of clay surrounding cast in situ piles," Geotechnical \& Geological Engineering, vol. 29, no. 1, pp. 57-63, 2011.

[5] Z. L. Zong, X. L. Lu, and Q. S. Li, "Comparative test study on compressive and uplift resistance of static pressure steel pipe grouting micro-piles," Geotechnical Mechanics, vol. 39, no. S1, pp. 362-368, 2018, in Chinese.

[6] Q. Abbas, W. Choi, G. Kim, I. Kima, and J. Leeb, "Characterizing uplift load capacity of micropiles embedded in soil and rock considering inclined installation conditions," Computers and Geotechnics, vol. 132, pp. 1-12, 2021.

[7] H. Seo, M. Prezzi, and R. Salgado, "Instrumented static load test on rock-socketed micropile," Journal of Geotechnical and Geoenvironmental Engineering, vol. 139, no. 12, pp. 2037-2047, 2013.

[8] D. A. Bruce, I. Juran, and A. F. Dimillio, "High capacity grouted micropiles:the state of practice in the United States," in Proceedings of the 15th International Conference on Soil
Mechanics and Geotechnical Engineering, pp. 851-854, Cambridge University Press, Istanbul, Turkey, August 2001.

[9] F. M. Abdrabbo and K. E. Gaaver, "Simplified analysis of laterally loaded pile groups," Alexandria Engineering Journal, vol. 51, no. 2, pp. 121-127, 2012.

[10] G. Russo, "A method to compute the non-linear behaviour of piles under horizontal loading," Soils and Foundations, vol. 56, no. 1, pp. 33-43, 2016.

[11] D. Kyung and J. Lee, "Uplift load-carrying capacity of single and group micropiles installed with inclined conditions," Journal of Geotechnical and Geoenvironmental Engineering, vol. 143, no. 8, pp. 17-31, 2017.

[12] R. Salgado, F. S. Tehrani, and M. Prezzi, "Analysis of laterally loaded pile groups in multilayered elastic soil," Computers and Geotechnics, vol. 62, pp. 136-153, 2014.

[13] H. Tahghighi and K. Konagai, "Numerical analysis of nonlinear soil-pile group interaction under lateral loads," Soil Dynamics and Earthquake Engineering, vol. 27, no. 5, pp. 463-474, 2007.

[14] N. G. Salisbury and S. A. Davidow, Current Design and Construction Practices for Micropile Supported Foundations of Electrical Transmission Structures in North America, pp. 1-7, International Society for Micropiles, PA, USA, 2014.

[15] Z. Chen, L. Mei, and G. X. Mei, "Numerical simulation of lateral bearing capacity of flexible micropile," Rock and Soil Mechanics, vol. 32, no. 7, pp. 2219-2224, 2011, in Chinese.

[16] J. Lee, Y. Kim, and S. Jeong, "Three-dimensional analysis of bearing behavior of piled raft on soft clay," Computers and Geotechnics, vol. 37, no. 1, pp. 103-114, 2010.

[17] J. Cho, J. H. Lee, S. Jeong, and J. Lee, “The settlement behavior of piled raft in clay soils," Ocean Engineering, vol. 53, pp. 153-163, 2012.

[18] A. M. Alnuaim, M. H. El Naggar, and H. El Naggar, "Performance of micropiled rafts in clay: numerical investigation," Computers and Geotechnics, vol. 99, pp. 42-54, 2018.

[19] G. M. Álamo, A. E. Martínez-Castro, L. A. Padrón, J. J. .Aznáreza, R. Gallego, and O. Maesoa, "Efficient numerical model for the computation of impedance functions of inclined pile groups in layered soils," Engineering Structures, vol. 126, pp. 379-390, 2016.

[20] Standard of the People's Republic of China, "Standard for geological testing method," China Planning Press, Beijing, China, 2019, in Chinese.

[21] Standard of the people's Republic of China, "Standard for Test Method of concrete Structures," China Building Industry Press, Beijing, China, 2012, in Chinese. 